\title{
A flood resilience observatory in French Polynesia: results and research perspectives from the ILOTS project
}

\author{
Bourlier $\mathrm{B}^{1,2}$., Taillandier $\mathrm{F}^{1}$., Heinzlef $\mathrm{C}^{2}$., Curt $\mathrm{C}^{1}$., Davies, $\mathrm{N}^{3}$., Serre $\mathrm{D}^{2}$. \\ ${ }^{1}$ Irstea, UR RECOVER, Aix-en-Provence, France \\ ${ }^{2}$ EIO - Ecosystèmes Insulaires Océaniens (UMR 241), Université de Polynésie Française \\ ${ }^{3}$ University of California Berkeley, GUMP Station, Moorea
}

\begin{abstract}
It has been pointed out that the French overseas territories are very concerned by flash floods, but this risk is poorly addressed by the national Government and local authorities. The need to innovate in flood risk management approaches in such areas is explained in particular by the awareness of the lack of consideration of vulnerable territories. This work aims to, first, providing a model to assess the level of resilience of Tahiti and Moorea to flooding. Secondly, it lays the foundations for long-term research with the design of a risk and resilience Information System in the Pacific islands being the start of a future territorial observatory. A first step of our work was to provide some contextual elements as well as perspectives for assessing resilience in the territories of Tahiti and Moorea in French Polynesia. Then, we set up different approaches for assessing resilience and try to operationalise this concept to finally develop a global model adapted to these particular territories.
\end{abstract}

\section{Introduction}

In a context of climatic change - and global warming - natural disasters have increased by about $2 \%$ per year in the world over the last 15 years (CRED, 2015). Among these disasters, the risk of flooding seems to be the most "damaging" worldwide (Vinet et al., 2012). Indeed, since 1960, the number of floods has considerably increased, reaching more than 600 events for the year 2007 (Zevenbergen, 2005) : for example, in 2013, "the damages caused by floods were 90\% higher than their 2003-2012 annual averages" (Pescaroli and Nones, 2016). Although the number of deaths has decreased in the face of this risk, floods remain the most costly natural disasters, estimated to cost "100 billion euros per year by the end of the century" (Barroca, DiNardo and Mboumoua, 2013).

At the same time, the increasing complexity of socio-technical systems makes flood risk management difficult. Nowadays, half of the world's population has become urban, an accelerated phenomenon of these last ten years (Serre, 2011). The concentration of the population in urban areas contributes to increasing flood risks in these areas. Urbanization increased from $10 \%$ in the 1990 s to $50 \%$ in just two decades (Meerow, Newell and Stults, 2016). This very rapid process has increased the vulnerability of the territory because cities are not prepared or equipped to manage the needs of such a concentration of population, especially

${ }^{a}$ Corresponding author: damien.serre@upf.pf

DOI 10.3311/FLOODRisk2020.25.2 when risk situations arise. The population, due to the lack of available land, comes to settle in areas at risk. Previously free spaces are gradually being eaten away by urbanisation without respecting the natural functioning of watersheds, rivers... leading to impermeable soils, preventing the necessary infiltration of rainwater.

While urban systems should make it possible to ensure the security and development of populations, recent climate-related disasters around the world (Hurricane Katrina in New Orleans (United States), 2005; storm Xynthia (France), 2010; floods in Paris (France), 2016; storm Ophelia in Ireland, 2017; hurricanes Harvey and Maria (United States), 2017; etc.) have revealed the vulnerability of cities to such events (Quenault, 2013). For more than ten years, experts questioned new ways of managing risks. In politics, economics, urban planning, architecture and scientific research, there is now a growing emphasis on strategies to make urban systems both less vulnerable and more resilient to climate-related disasters, while meeting the long-term challenges of sustainability and quality of life (Quenault, 2014). Recent risk management objectives from international authorities (United Nations, 2016) are to establish a new risk management able to make a transition to a general culture of risk prevention and mitigation" (European Commission, 2013). This has led researchers and managers to examine new approaches 
to managing natural hazards. One of these is based on the concept of urban resilience (Serre, 2011).

But not all organization are at the same level of maturity in terms of risk management approaches. Many particularly vulnerable territories have very limited and deficient natural risk management systems. This is the case, in particular, of the French overseas territories. Thus, in September 2014, a French interministerial report on flash flood risks concluded that French overseas territories are very concerned by flash floods but that this risk is poorly taken into account by the national government and local authorities (Bourgeois et al., 2015). Indeed, overseas territories are highly exposed to hurricanes, earthquakes and tsunamis, but especially flash floods risks are not sufficiently taken into account, notably compared to other French territories. The report also highlights a sharing of responsibilities for poorly controlled risk management processes between national and local authorities. At the same time, local authorities seem, on the one hand, reluctant to engage fully in risk management and, on the other hand, face a lack of control over land and urban development. The report also makes some recommendations to improve risk management strategies abroad, among which the development of decision support systems is a priority. Since 2014, some actors have tried to address some of these issues, but separately at this stage and without sufficient support from national and local authorities.

A major challenge in this context, combining increasing risk and weakness of risk management in overseas territories, consists in ensuring a change in the risk-resilience paradigm in order to improve territory resilience. This communication is in line with this theme. This work is carried out during a Ph.D thesis (INRAE, UPF) and is part of the ILOTS project (CNRS and IRD), which aims answering this challenge by questioning the resilience of overseas territories to specific natural risks such as flooding and marine submersion. The territories under study are more particularly the upper islands of French Polynesia concerned by these risks, and the work focuses on Tahiti and Moorea. This work deals with two main objectives:

- Providing a model to assess the level of resilience of Tahiti and Moorea to flooding;

- Laying the foundations for a long-term research with the design of a risk and resilience Information System in the Pacific islands being the start of a future territorial observatory

Ultimately, the aim is to help stakeholders to prioritize actions strategically in terms of land use planning, and to face the challenges of risks in a context of global change by improving the resilience of their territory.
In this paper we will first present the concept of resilience as applied to flood risk and the prospects in terms of operationalization. Then we will present the interest to develop an observatory in French Polynesian territory. Finally, we will propose perspectives for the application of resilience assessment models on the territories of Tahiti and Moorea.

\section{Research framework and local context}

\subsection{Risk exposure and vulnerability of Polynesian territory to flooding}

In September 2014, a French interministerial report on flash flood risks concluded that the French overseas territories are very concerned by flash floods but that this risk is poorly taken into account by the national government and local authorities compared to the French hexagon. However, several combined factors of the overseas territories, such as geography, climate, land use planning constraints and social structures, increase the vulnerability to flash floods and to risks in general. The report also highlights a sharing of responsibilities between the national and local authorities in risk management processes. For example, the officials from France's overseas territories are not represented in a national commission responsible for preparing prevention plans to deal with flash floods. In addition, the national risk observatory does not cover the overseas territories. At the same time, the local authorities are poorly involved in risk management, except for hurricane-related issues, because of the population's good culture of dealing with this type of hazard. A crucial problem is the lack of control of the local authorities over land and urban development which tends to increase the vulnerability of the territory.

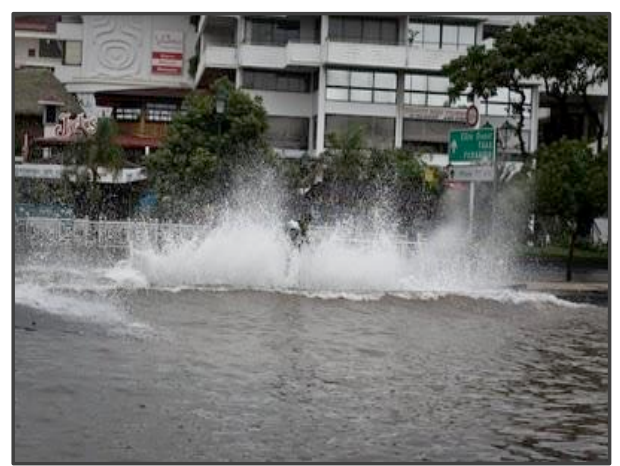

Illustration 1. Flooding of the Papeete waterfront during cyclone OLI in 2010 (BRGM, 2013) 


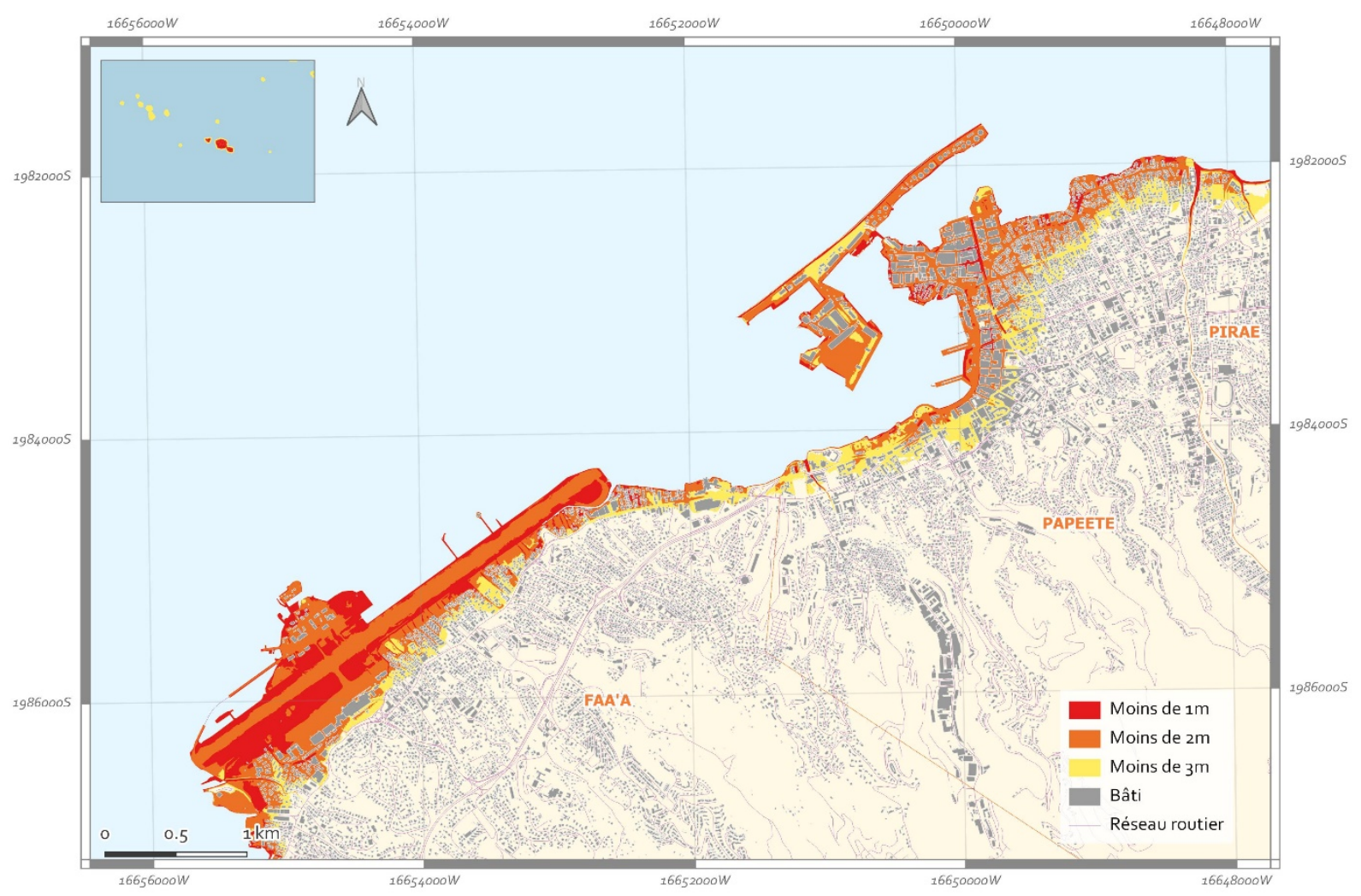

Figure 1. Extent of the low-lying areas in Papeete and Faa'a municipalities (source: LIDAR SHOM)

The report also makes some recommendations for improving risk management strategies in the overseas and in particular on how to take into account the ultramarine context in risk reduction strategies. The report brings together some crucial topics on which efforts are expected to be made:

- Coastal flooding caused by hurricanes;

- The conjunction of coastal submersion and river flooding;

- Runoff in the tropics;

- The impacts of climate change.

For the purposes of this work, the study territory will be French Polynesia and in particular the islands of Tahiti and Moorea located in the Society Islands. The capital, located in Tahiti, is the conurbation of Papeete (170,000 inhabitants), which includes a large part of the Polynesian population as well as most of the major services and infrastructures. Indeed these islands are vulnerable to the risks of flooding and marine submersion in particular. French Polynesia has recently been hit by major cyclones, particularly Oli in 2010, which affected the Society Islands and the Austral Islands. The cyclone passed $300 \mathrm{~km}$ from Tahiti during the night of February 3-4, 2010, with some overflows on the city of Papeete (Illustration 1). The vulnerability of Papeete is partly linked to the high urban density in low areas (figure 1).

Moreover, it is interesting to specify the actors of risk in French Polynesia, which is a territory obeying its own issues within an original institutional framework.

First of all, we can identify that many competences fall to the Government of French Polynesia. The Polynesian government is competent for all aspects of risk prevention (Risk Prevention Plan (PPR), general town planning, General Development Plan (PGA), preventive information).

The Polynesian government is preponderant in the decision-making process, as illustrated by the approval procedure for PPRs in Polynesia, which consists of a round trip between the Council of Ministers and the municipalities concerned. The government is associated with all of the departments responsible for risk management, starting with the urban planning department (SUT). The municipalities are in charge of the PCS shared with French state. Then French State is responsible for crisis management and civil security with, for example, the implementation of the CYCLONE emergency plan (information, alert, evacuation).

An analysis of the risk management system on the territory of French Polynesia, and in particular on Tahiti and Moorea, highlights many shortcomings. First of all, there is a lack both in the diversity of risk management plans but also in the small number of them that have been set up.

Indeed, only one PPR (risk prevention plan) has been approved on Tahiti in the municipality of Punaauia. Another was approved in Rurutu on the 
southern islands. In addition, there are special indications about flooding in the General Development Plans (Urbanism, Land planning) that are intended to be developed. The main explanation of this lack of PPR is the difficulty for decision-makers to implement them and land tenure.

The implementation of these management plans faces many difficulties in general, and French Polynesia is not an exception. Indeed, the land context is very particular with many undivided properties or "land deals" that do not allow to clearly establish an owner for each parcel. This leads to numerous disputes giving rise to numerous court cases (Stahl, 2018). For example, on 10 September 2005, an exceptional southern swell phenomenon affected French Polynesia. In Bora-Bora, the swell destroyed five detached houses and flooded more than a hundred hotel dwellings. Five years later, thirty-five affected houses were still waiting to be rebuilt because the property problems had not been resolved (Canavesio, Jeanson and Étienne, 2014). Indeed, a major characteristic of Polynesian land ownership is that "amicable exit from undivsion before a notary is the exception, while judicial division appears to be the rule" (Bambridge et al., 2012). In addition, there are other problems to be identified, for example, there is little or no insurance in case of crisis. Moreover, there is a mistrust of local policies towards these risk management documents, which are perceived as restrictive and cause real blockages in the procedures for implementing PPR. Finally, there is a low number of PCS (crisis management) actually implemented (status of JMPs to be checked...). Finally, the prospective part is not present at all in the PPR (Stahl, 2018) in regions where taking climate change into account should be a priority. Thus, the risk management procedures are largely to be improved in these islands, and an approach for the risk management seems to be an important step in characterizing the structural and organizational deficiencies and vulnerabilities of the territory.

Thus, in view of the risks present in this territory and the inherent structural and organisational vulnerabilities, assessing resilience with an operational approach seems relevant.

\subsection{Resilience and risk management}

The concept of resilience has been discussed in scientific literature on risks and disasters (White and Hass, 1975) since 1970s but was really investigated in at the beginning of the 21 st century, both politically and scientifically. Politically, the Hyogo World Conference on Disaster Risk Reduction (January 2005), highlighted the need to build disaster-resilient nations and communities. Height months after this conference, scientific work shown that the floodrelated disaster caused by Hurricane Katrina revealed weaknesses in prediction and prevention, as well as the insufficient organization of those in charge of crisis management, particularly in New Orleans. This event, which is only one among many on a global scale, demonstrates the need to prepare for "systemic" disasters and crises. Katrina mobilized the world of research, which revisited the concept of resilience, notably to analyze the traditional models of response to an unexpected event and the post-crisis management mechanisms. More recently Sendai conference in 2015 also developed resilience concept. Thus, widely used in recent years in political and scientific discourse on the question of risks, resilience has become the new framework, the new benchmark for disaster management policy.

The concept of resilience is increasingly used in various scientific and societal fields: ecology, psychology, geography (populations and territories faced with risks), risk analysis, politics and the banking and insurance sectors, etc. It is now acknowledged that the term hides a variety of meaning depending on the disciplines and context in which it is used (Provitolo, 2009). In the field of risks and disasters, which includes flood risk, analysis of the scientific literature reveals that there is not one but several types of resilience, although, paradoxically, the term "resilience" is mainly used in the singular, in both scientific and political discourse. In territorial, operational and institutional, but also biological and psychological field, resilience describes a capacity, or several capacities. We can distinguish various types of these capacities (Twigg, 2009; Reghezza-Zitt, Provitolo and Lhomme, 2015; Curt and Tacnet, 2018) according to the timeframes : before, during and after a shock.

Thus, before the shock, resilience refers to:

- the capacity to anticipate, especially unpredictable and inconceivable scenarios, in order to ensure the operational capacities of systems and organizations, even in "damaged mode";

- the capacity to manage or preserve the essential functions, structures and organizations in order to adapt them to a future situation (anticipative adaptation);

- the capacity to learn.

During the event, resilience can correspond to:

- $\quad$ the capacity to resist and cope with a shock;

- the capacity to absorb a shock, which involves a degree of flexibility. 
After the shock, resilience reveals:

- the capacity to recover and rebuild, here or elsewhere. These capacities mobilize a system's internal and/or external resources, whether it is an individual, a neighborhood, a town, a country, etc.;

- a system's capacity to maintain its integrity and return (or bounce back) to either the former state of balance or a new state;

- an individual or community's capacity to adapt, to take advantage of a negative situation and to renew and transform the system.

These meanings are not always compatible and lead to passionate debates, notably on the ideas of "resistance to" or "absorption of" a shock. They are synonyms for some people, combining resistance and persistence, implying that persistence involves force and duration, and closely connected for those who believe that resistance gives the system time to adapt, whereas the two concepts are entirely opposite for those for whom the capacity to adapt assumes suppleness and flexibility, while resistance implies opposition and rigidity (Adger, 2000). It is also possible to adopt a stance somewhere between the two. Indeed, although some forms of hazard attenuation can increase resilience, others can "sap" it in the long term (Burby, 2006; Boin, Comfort and CC, 2010). It all depends on the type of hazard (recurrent and anticipated versus exceptional and unanticipated). For example, during a flood, collective defense structures, such as levees and anti-tsunami walls, can contribute to the resilience of a territory for a type of risk and given intensity, confining the hazard by limiting damage, thereby helping the system to recover faster. But these structural defense mechanisms can also create and even reinforce population vulnerabilities (Pigeon, 2012) during exceptional and unanticipated hazards. Xynthia storm which crossed Western Europe between 26 and 28 February 2010, showed that these defense structures, due to their intrinsic vulnerability, do not provide absolute protection and sometimes give the population a false sense of security.

All these definitions share one idea, however: a system's balance and recovery or renewal require capacities of absorption and anticipative or reactive adaptation to shocks, particularly in a changing environment. Resilience is built up before a shock, expressed during the event or crisis and continues to build after the event. Resilience does not therefore concern only the reconstruction phase, but unfolds over one timeframe in three periods: before, during and after the disaster, whether it is abrupt and unexpected (flash flooding, local tsunami), or continuous (drought).
Furthermore, defining the concept of resilience involves identifying a territory for analysis. Many studies focus on the urban system, in which case resilience is measured through the study of complex systems such as cities. Thus, we speak of so-called functional resilience with regard to the maintenance in service of the critical infrastructures of the city (Lhomme, 2013). It should be noted that until recently the concept of resilience was most often limited to the design of buildings and more rarely to the perception of technical systems as a whole. Thinking at the scale of a system makes it possible to have a comprehensive approach to resilience. It is then obvious to speak of a system to characterize the functioning of the city. The study of urban resilience will also lead to the identification of Critical Infrastructures which in our case can be the networks in question but also other components of the city. The figure below also shows us the interest of a multi-scalar vision of urban resilience (neighborhood, city, region, watershed in some cases) with critical infrastructures that can be apprehended at different levels and that can impact the system in different ways depending on the scale observed (Barroca, DiNardo and Mboumoua, 2013). The work on urban resilience also makes it possible to reflect on the choice of the most relevant scale for the analysis. The urban system will function differently depending on the scale selected. When we talk about the resilience of the city, the neighborhood scale is quite present. It is relevant in terms of planning and designing a resilient system on a limited scale. In the end, defining resilience in the context of risk management involves looking at all aspects of risk and crisis and understanding how this notion is relevant to understanding temporalities, scales, as well as territories and their components. A certain number of models have been developed to clarify and then assess resilience.

\section{Assessment methodology}

We present in a first part the main bottlenecks regarding the operationalization of resilience concept. Two main questions arise above all, that of the relevant scale of the analysis on the one hand and that of taking temporality into account on the other. Next, we will study the relevance of existing models and the questions of operationalization raised in this framework.

\subsection{Scientific bottlenecks specific to the territory}

The concept of resilience allows, and implies, to apprehend the response capacities of the territory at several scales especially in urban resilience fields (Barroca, DiNardo and Mboumoua, 2013). The 
studied territory has the particularity of being an insular, constrained, very unevenly populated and urbanized territory.

We first consider two islands: Tahiti and Moorea with very different characteristics and strong internal disparities. Thus an approach that will be described as "multi-scale" is required for the continuation of this work in order to be able to consider the disparities of the territory. Changing the scale of the analysis may, in this case, make it possible to address several aspects of resilience for a vision that is as inclusive as possible, ranging from the resilience of coastal, island and urban areas. Each with its own specificities. Thus we observed three distinct analyses scales:

- The Tahiti/Moorea system (links, infrastructure repairs, imbalances, etc.)

- The urban area of Papeete

- A neighbourhood exposed to risks (submersion/flooding). The neighbourhood can be defined as: "a part of a city with its own appearance and characterized by distinctive features that give it a degree of unity and individuality" (Merlin and Choay, 2009).

Moreover, this work is intended to make questions of temporality one of the main axes of future reflection. It was highlighted that resilience implies the occurrence of a crisis and the taking into account of elements upstream of the crisis, elements during the crisis (effectiveness of crisis management...) and elements of recovery after the crisis. The assessment of resilience must go through all these stages. This can be done through a diversity of indicators that reflect these temporalities, or through a more qualitative analysis of governance according to these same temporalities.

Furthermore, the notion of long-term resilience has been put forward, and while taking into account the trajectory of resilience for a territory seems relevant for a complete approach to the concept, assessing this phenomenon seems rather difficult. This should involve taking into account older phenomena and assessing the long-term evolution of all aspects of resilience, from a technical but also socio-economic and even environmental point of view. Indeed the concept of resilience could cover a more or less multidimensional approach.

In any case, taking into account the temporalities of the crisis as precisely as possible seems to be a priority for the production of relevant information for local development stakeholders.

\subsection{Develop a methodology based on multi scale approach}

A first stage of the work will involve applying existing methods and models from literature for assessing resilience. Two models, corresponding to two approaches of resilience operationalization will be investigated: the DS3 method (Serre, 2011; Lhomme et al., 2013), and the application of a set of indicators (Cutter, Ash and Emrich, 2014; Heinzlef, Becue and Serre, 2019). These different models implement different conceptions of resilience and therefore operate at different scales.

\subsubsection{Application of DS3}

The DS3 model, built on the the systemic approach, focuses on the capacity of technical systems to cope with floods. Its interest is to take into account several aspects of the concept of resilience such as the notion of urban system but also the concepts of absorption and rebound when facing the crisis. These studies (Balsells et al., 2013; Serre et al., 2018) have focused on modelling a neighbourhood system. This method uses the concept of Functional Analysis. The objective of functional analysis is to establish a structural analysis of a system, to define the system boundaries, its environment, and then to define the components of this system and associate functions to them (Serre et al., 2018). Then, it is possible to observe the failures of the system, at different period of the crisis. This method shows the interdependence of the networks and critical infrastructures of the studied area. Thus we can observe the domino effects and the notion of impact chains. For example, an electricity generator breakdown could impact a lot of other components and networks or very few.

Thus this method give one main tool to describe a system, the Functional Diagram, it help to understand relationship between components (Lhomme $\mathrm{S}$ et al., 2010). This method seems very suitable for work at the neighbourhood scale and in particular for the technical components of the neighbourhood. This scale should allow to work in a rather detailed way and to identify the main components of the neighbourhood system in this flood risk context. The neighbourhood should be seen as a social, economic and technical system and be considered in its entirety (Serre et al., 2018). 


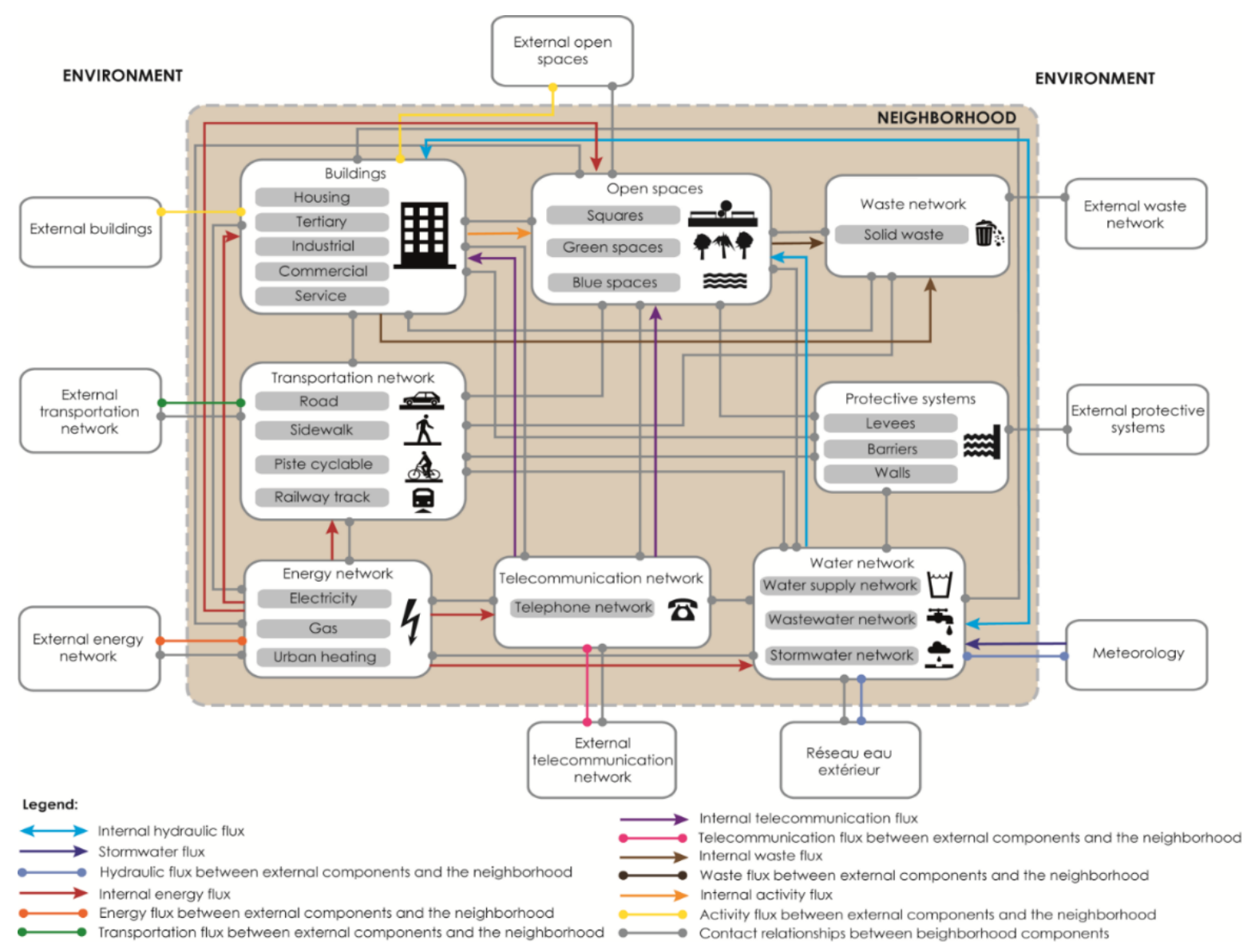

Figure 2. Functional diagram of the neighbourhood system (Serre et al, 2018)

Figure 2 provides a proposal for modelling the neighbourhood system in a flood risk context. This network-based system is intended to be comprehensive by taking into account as many components as possible. In this case, the neighbourhood is organized into components that are all connected. These relationships are called flows, flows of energy, of people, waste... The idea is to apply the principles of DS3 to the study area by going beyond the analysis of one or several technical networks.

Thus, in a first step, the work consisted in taking up the structure of the neighbourhood system developed within the framework of DS3 (Serre et al., 2018) and adapting it to the Polynesian context and to Papeete in particular. In addition to the technical components, it seemed relevant to add elements related to governance and the actors' competences on the different elements of the system. Thus, the first step is to take up the structure of the neighbourhood system developed within the framework of DS3 (D. Serre et al. 2018) and adapt it to the Polynesian context and to Papeete in particular.

In addition to the technical components, it seems relevant to add the elements related to governance and the actors' skills on the different elements of the system. The prism of the risk management systems and the skills of the actors will be enhanced. This approach through risk governance is therefore original and different from the work already carried out in this framework. This initial analysis is first of all of interest in the diagnosis of the territory. Schematizing all of the relationships and skills of the players involved in risk management provides a clear vision of the situation and then possibly an assessment of organizational blockages.

\subsubsection{Application of an indicator grid}

The second type of investigated approach is based on a set of indicators, widely developed in various forms and applied to the city of Avignon by Charlotte Heinzlef (Heinzlef, Becue and Serre, 2019). The indicators selected in this work was based on several works, including the BRIC method (Cutter et al., 2008). This approach proposes a broad and inclusive vision of the notion of resilience. The figure 3 summarizes the classes of indicators. 


\begin{tabular}{|l|l|}
\hline SOCIAL Resilience & $\begin{array}{l}\text { URBAN Resilience } \\
\text { Ages of population } \\
\text { Employment }\end{array}$ \\
$\begin{array}{l}\text { Social security/health of construction of the } \\
\text { Level of education }\end{array}$ & $\begin{array}{l}\text { Presidences } \\
\text { infrastructure }\end{array}$ \\
\hline
\end{tabular}

TECHNICAL Resilience

Network Accessibility

Diversity of the network

Figure 3. Example of a resilience indicator with an inclusive vision (Heinzlef, 2019)

This method is particularly relevant on a large scale that takes into account different realities, whether on the scale of an urban area or an archipelago (Tahiti-Moorea system). However, a certain number of questions arise in setting up such indicators. Firstly, on, it seems possible to broaden the diversity of the indicators taken into account and specify some of them. Technical resilience could be specified: for example, better consider the networks (water, energy, etc.), but also the state of the built environment (type of building, heights, functions, etc.) could increase the accuracy of the assessment and then improve the method. Moreover, it will also be interesting to integrate governance dimension into the evaluation of resilience.

Last but not least, one question remains. That of the scale of analysis. Some work shows that INSEE's IRIS scale could prove to be particularly relevant in urban areas, as it takes into account what could be assimilated to neighbourhoods in the urban area (Heinzlef, Becue and Serre, 2019). However, administratively, regarding data collection, this precise scale does not exist in Tahiti. We will therefore have to find a relevant scale adapted to out specific context. A discussion with the urban planning services on the divisions used locally is relevant in this regard.

\section{Towards the development of an observatory}

The aim of this work is to set up a resilience observatory adapted to the Polynesian islands. Thus the elements developed in this work are intended to fit into the architecture of this future observatory. We can define an observatory as an "observation system set up by one or more organisations to monitor the evolution of a phenomenon, an area or a portion of a territory in time and space; most Observatories take the form of computer applications in which data are aggregated and presented in the form of tables, maps or statistical indicators" (IETI Consultants, 2002). Many observatories exist in geography, in many fields and in particular regarding risks. There are observatories of institutional origins (national, regional) but also observatories of more local origins linked to very varied actors.

An observatory is most often built around a theme or a territory. It will bring into play tools for providing information, but also for disseminating this information. An observatory will then respond to global or specific needs. This notion is at the crossroads of the fields of information, technology but also cognition, all of this relating to a given territory, here the islands of Tahiti and Moorea. So, there are several issues to be clarified in order to builds an observatory. What is the objective of this observatory? A decision-making tool or simply statistical monitoring? Who will be the public concerned by the tool? Public decision-makers, managers, the general public? What will be the temporalities taken into account by the tool?

In our case, it turns out that the purpose of the object will be to support the decision-makers in charge of the development on the territory of Tahiti and Moorea. The objective will then be to valorise an original data, useful to managers in a perspective of aiding reflection on the various policies relating to risk management in French Polynesia. Furthermore such a tool could be shared by a wider range of users such as research organizations or general public.

Beyond the conceptual framework, many technical questions arise in order to answer the identified objective, ranging from data management to Web-GIS (client-server) architectures. In fact, it has been pointed out that the development of such a tool is to be linked to a database with mostly a geographical vocation (shapefile data for example). These data has to be updated and modified it's an essential element to lay the foundations of such a tool. In addition to the database, the observatory must be able to provide a dashboard giving direct access to a certain amount of information and facilitating the accessibility of them for each user, according to her/his specific needs. Last but not least, the mapping tool is an essential component of the object. In this sense free solutions will be favoured to allow both flexibility in use and accessibility to the greatest number.

In this way, developing the bases for the creation of a future observatory will enable us to a better understanding of the complexity of the study area.

Developing a relevant decision-support tool requires a precise understanding of the issues of risk governance on the territory. Finally, developing such a tool implies co-construction; the elaboration process must be participatory, integrating the stakeholders, in order to be meaningful for them and then really used. 


\section{Conclusion}

The development of the concept of resilience in risk management is a relatively recent occurrence, remaining relatively imprecise, and difficult to implement. However, the scientific production around this concept makes it possible to respond pertinently to most risk management issues. In the same way, the development of operational models is highly variable in the definition of the concept and in the dimensions taken into account by the model (thematic, temporal dimensions, etc.).

A first step of our work was to provide some contextual elements as well as perspectives for assessing resilience in the territories of Tahiti and Moorea in French Polynesia. The idea is, then, to set up two different approaches for assessing resilience. The first approach results from the functional analysis and the study of technical networks, but with the vocation to be holistic and proposing a more qualitative and fine analysis in its diagnosis. The second approach is an approach based on the implementation of quantified indicators over a wider area (urban area, archipelago).

These two approaches to assessing resilience are quite different, but we will assume that they are complementary, allowing for a comprehensive approach to the concept of resilience. The challenge is to adapt these methods in order to implement a continuity in the analysis at the different scales of the territory. Above all, these methods will have to reflect the same definition of the concept.

The aim of this project is to integrate the data produced by the resilience assessment into an observatory. The idea of sharing data through an observatory is a real step towards the creation of a tool to assist reflection and even decision-making in a territory whose needs in this area have been clearly identified.

\section{Acknowledgement}

This project has received financial support from the CNRS through the MITI interdisciplinary programs and from the IRD.

\section{References}

1. Adger, W. (2000) 'Social and Ecological Resilience: Are They Related?', Progress in Human Geography, 24, pp. 347-364. doi: 10.1191/030913200701540465.

2. Balsells, M. et al. (2013) 'Urban design contribution to neighbourhood flood resilience: proposition of a model analysis', International conference on flood resilience: experiences in Asia and Europe, (September), pp. 1-11.

3. Bambridge, T. et al. (2012) 'La gouvernance du système économique polynésien en question Comment protection et absence de concurrence obèrent la croissance To cite this version: HAL Id : halshs-00722690 La gouvernance du système économique polynésien en question Comment protection'.

4. Barroca, B., DiNardo, M. and Mboumoua, I. (2013) 'De la vulnérabilité à la résilience : mutation ou bouleversement ?', EchoGéo, (24), pp. 0-18. doi: 10.4000/echogeo.13439.

5. Boin, A., Comfort, L. and CC, D. (2010) 'The Rise of Resilience', in, pp. 1-12.

6. Bourgeois, P. et al. (2015) Evaluation du plan de prévention des submersions rapides dans les Outre-Mer.

7. Burby, R. J. (2006) 'Hurricane Katrina and the Paradoxes of Government Disaster Policy: Bringing About Wise Governmental Decisions for Hazardous Areas', The ANNALS of the American Academy of Political and Social Science. SAGE Publications Inc, 604(1), pp. 171191. doi: 10.1177/0002716205284676.

8. Canavesio, R., Jeanson, M. and Étienne, S. (2014) 'La gestion du risque cyclonique en Polynésie française et ses limites: Exemple du cyclone tropical Oli, février 2010', Bulletin d'Association de Geographes Francais, 91(3), pp. 325-337.

9. Curt, C. and Tacnet, J. M. (2018) 'Resilience of Critical Infrastructures: Review and Analysis of Current Approaches', Risk Analysis, 38(11), pp. 2441-2458. doi: 10.1111/risa.13166.

10. Cutter, S. L. et al. (2008) 'A place-based model for understanding community resilience to natural disasters', Global Environmental Change, 18(4), pp. 598-606. doi: 10.1016/j.gloenvcha.2008.07.013.

11. Cutter, S. L., Ash, K. D. and Emrich, C. T. (2014) 'The geographies of community disaster resilience', Global Environmental Change. Elsevier Ltd, 29, pp. 65-77. doi: 10.1016/j.gloenvcha.2014.08.005.

12. Heinzlef, C., Becue, V. and Serre, D. (2019) 'Operationalizing urban resilience to floods in embanked territories - Application in Avignon, Provence Alpes Côte d'azur region'. Elsevier, 118(February), pp. 181-193. doi: 10.1016/j.ssci.2019.05.003.

13. Lhomme, S. et al. (2013) 'La résilience de la ville de Dublin aux inondations: de la théorie à la pratique', Environnement, Nature, Paysage, pp. $1-19$.

14. Lhomme, S. (2013) Les réseaux techniques comme vecteur de propagation des risques en milieu urbain Une contribution théorique et pratique à l'analyse de la résilience urbaine. 
15. Lhomme S et al. (2010) Résilience urbaine et réseaux techniques: Une approche par l'analyse spatiale pour une évaluation possible de la résilience urbaine. Available at: http://www.geographie.ens.fr/IMG/file/resilience /pres-ens.pdf.

16. Meerow, S., Newell, J. P. and Stults, M. (2016) 'Defining urban resilience: A review', Landscape and Urban Planning. Elsevier B.V., 147(March), pp. 38-49. doi: 10.1016/j.landurbplan.2015.11.011.

17. Merlin, P. and Choay, F. (2009) 'Dictionnaire de l'urbanisme et de l'aménagement', in.

18. Pescaroli, G. and Nones, M. (2016) 'Cascading Events, Technology and the Floods Directive: future challenges', E3S Web Conf., 7. Available at:

https://doi.org/10.1051/e3sconf/20160707003.

19. Pigeon, P. (2012) 'Apports de la résilience à la géographie des risques: 1'exemple de La Fautesur-Mer (Vendée, France)', VertigO, 12, pp. 021. doi: 10.4000/vertigo. 12031.

20. Provitolo, D. (2009) 'Vulnérabilité et résilience : géométrie variable des deux concepts Le domaine des risques et catastrophes', Séminaire résilience, p. 42.

21. Quenault, B. (2013) 'Du double affrontement ontologique/axiologique autour de la résilience aux risques de catastrophe: les spécificités de l'approche française', VertigO - la revue électronique en sciences de l' environnement, 13(3), pp. 1-41.

22. Quenault, B. (2014) 'La résurgence/convergence $\mathrm{du}$ triptyque «catastrophe-résilienceadaptation» pour (re)penser la «fabrique urbaine » face aux risques climatiques', Développement durable et territoires, pp. 1-34.

23. Reghezza-Zitt, M., Provitolo, D. and Lhomme, S. (2015) 'Définir la résilience: quand le concept résiste', in Magali, R.-Z. and Samuel, R. (eds) Résiliences - sociétés et territoires face à l'incertitude, aux risques et aux catastrophes. Available at: https:/halshs.archivesouvertes.fr/halshs-01161595.

24. Serre, D. (2011) La ville résiliente aux inondations Méthodes et outils d'évaluation. Available at: https://tel.archives-ouvertes.fr/tel00777206.

25. Serre, D. et al. (2018) 'Contributing to urban resilience to floods with neighbourhood design: the case of Am Sandtorkai/Dalmannkai in Hamburg, Journal of Flood Risk Management, 11, pp. S69-S83. doi: 10.1111/jfr3.12253.

26. Stahl, L. (2018) 'Les défis présents et à venir des plans de prévention des risques naturels polynésiensPresent and Future Challenges of French Polynesia Natural Risks Prevention Plans', Études Caribéennes, (41), pp. 0-24. doi: 10.4000/etudescaribeennes. 13106.

27. Twigg, J. (2009) Characteristics of a Disaster Resilient Community, International Journal of Production Research. doi: 10.1890/100068.

28. United Nations (2016) 'Transforming our world : the 2030 agenda for sustainable development', Arsenic Research and Global Sustainability Proceedings of the 6th International Congress on Arsenic in the Environment, AS 2016. doi: 10.1201/b20466-7.

29. Vinet, F. et al. (2012) 'Le processus de production $\mathrm{du}$ risque «submersion marine» en zone littorale : l'exemple des territoires «Xynthia »', Norois, 222, pp. 11-26. doi: 10.4000/norois.3834.

30. White, F. and Hass, J. (1975) 'Assessment of Research on Natural Hazards', Colorado University, p. 487.

31. Zevenbergen, C. (2005) Urban Flood Management. 